\title{
Town sanitation worker fatally crushed while riding on the riding step of a refuse collection truck (Case \#: 18NY063)
}

\author{
NAICS: 924110 Waste management program administration
}

\begin{abstract}
Key words: refuse collection truck, riding step, rear step, vehicle backing up, struck by, crushed, refuse and recyclable material collectors, municipal sanitation department
\end{abstract}

\section{SUMMARY}

On November 14, 2018, a 60-year-old male municipal sanitation worker, who was on the exterior riding step of a refuse collection truck that was backing up, was crushed against a parked lawn service truck and then run over by the refuse collection truck. The decedent was employed by a town sanitation department. He was a helper on a threemen refuse collection crew consisting of two helpers and a driver who was the crew chief. On the day of the incident, the crew was doing residential curb-side pickups along a designated route. At approximately 2:30 p.m., the crew arrived at the last street of their collection route. The truck was to back approximately 0.34 miles all way to the end of the street before moving forward for the helpers to pick up garbage on right side of the street. While the truck was backing, the two helpers were riding on the riding steps. There was an SUV parked on the driver's side of the street, and a lawn service truck with a trailer parked on the right side of the street. The refuse collection truck backed approximately 330 feet and passed the SUV. When the driver was trying to back past the lawn service truck, his right-side mirror contacted the lawn service truck, and the impact broke the mirror. Due to the broken mirror, the driver could not see the right rear side of the truck where the decedent was riding. The driver continued backing and felt his truck contact the lawn service truck. He stopped and drove forward to pull away. According to the eyewitness, the victim was pinned and crushed in between the lawn truck and the refuse collection truck. As the refuse collection truck pulled away, the decedent fell to the ground, and he was subsequently run over by the rear right tire of the refuse collection truck. The crew member immediately called 911 and the Emergency Medical Services responded within minutes. The injured worker died on route to the hospital. The cause of death was hemorrhage due to blunt force torso trauma.

\section{INTRODUCTION}

At 2:30 p.m. on November 14, 2018, a 60-year-old male municipal sanitation worker, who was on the exterior riding step of a refuse collection truck that was backing up, was crushed against a parked lawn service truck. As the refuse collection truck pulled away from the lawn service truck, the worker fell off the riding step and was run over by the refuse collection truck. The decedent was employed by a town sanitation department. The New York State (NYS) Public Employee Safety and Health Bureau (PESH) investigated the incident. The New York State Fatality Assessment and Control Evaluation (NY FACE) investigator met with the PESH compliance officer to review the 
case information. The NY FACE investigator also reviewed the incident site photos, witness statements, police report, death certificate, worker training records, and sanitation department worker injury and illness logs. Representatives of the town and the town sanitation department provided additional case information. This report summarizes the findings of the NY FACE investigation.

\section{EMPLOYER}

The town where the incident occurred had a population over 750,000. Municipal solid waste and recyclable collection, transfer, and disposal services were provided by the town sanitation department (the employer of the decedent) and five other independent municipal sanitation districts.

The town sanitation department employed approximately 430 workers, including drivers, laborers, and sanitation workers, who were represented by a labor union. The shift hours were from 6 a.m. to 2 p.m. The refuse collection workers were "on task", which meant that they could leave work once they finished their assigned routes. Workers were permitted to ride the refuse collection trucks on the exterior riding steps providing they followed the American National Standards Institute (ANSI)'s safety requirement.

\section{EMPLOYER FATAL AND NONFATAL INJURY RECORDS}

The town sanitation department had another fatal incident in 2014, four years prior to this incident. The 2014 incident also involved a worker riding the exterior riding step of a refuse collection truck. The victim was a 25-year-old male sanitation worker who was employed by the town for 11 months. He was caught and crushed between the refuse collection truck he was riding and another town refuse collection truck in an intersection.

The town was self-insured with the town Human Resource Department keeping worker compensation and injury records. PESH requires that all public employers keep the Log of Work-Related Injuries and Illnesses Form (SH-900). According to the town's SH-900 logs, there were a total of 50 injury cases associated with workers using riding steps between 2014 and 2018. The workers suffered injuries from falling, slipping, and being caught, struck, or crushed.

It should be noted that in addition to the two fatalities the town sanitation department had, there was another municipal sanitation worker killed while riding on the riding step. The incident occurred in 2008, and the victim was a 33-year-old seasonal sanitation worker who was employed by one of the independent municipal sanitation districts that served the town. The worker was thrown from the riding step and died from severe head injuries while the refuse collection truck was moving faster than 10 miles per hour and travelling for distance greater than 0.2 miles. Overall, three municipal sanitation workers were killed while using the riding steps in this town between 2008 and 2018.

\section{EMPLOYER WRITTEN SAFETY PROGRAMS AND TRAINING}


The town sanitation department provided its employees with Class 2 ANSI reflective vests and gloves. Workers were required to wear them while collecting refuse. Employees were also required to wear safety boots.

The last department-wide safety training on refuse collection operation, which specifically addressed the hazards associated with using the riding steps, was provided in November 2014 in response to the first town sanitation worker fatality. The training, titled "Safe Refuse Truck Operation", was developed and delivered by the union. The training covered the refuse collection safety hazards, collection worker fatal injuries, and the regulations for using the refuse collection truck riding steps, such as the PESH Program Directive and the ANSI standard.

A department safety coordinator conducted daily checks on the refuse collection trucks. According to the town representative, veteran employees provided field training to new hires by walking them through the refuse collection procedure, including the safe use of riding steps. On arriving at a collection stop, the helpers got out of the truck and the driver rolled down the window so that the crew could verbally communicate. If needed, the helpers could act as spotters to help the driver navigate traffic. The helpers were to stay in the line of sight of the driver. Field training for the new hires was not documented in writing.

The sanitation department had developed a progressive discipline program with disciplinary actions ranging from written reprimands, loss of leave entitlements, and suspension without pay, to termination. The department records showed that four written disciplinary action notices were issued and three involved misuse riding steps. None of the offenders received any disciplinary action beyond the written reprimands.

The employer stated that the department safety officer randomly checked sanitation crews on their collection routes for their compliance with safety rules. The employer also stated that it was impossible for management to monitor all the trucks on all their collection routes. The management representative stated to the PESH investigator that as long as the steps were on the trucks, it was likely that the employees would misuse them.

The PESH investigator concluded that although employees appeared to be knowledgeable about the ANSI safety requirements, violations occurred often. The $\mathrm{PESH}$ investigation confirmed that there was general knowledge of ongoing and repeated employee violations of safety rules when using the riding steps. The progressive disciplinary program was not followed through. There had been discussions between management and the union on taking measures to remove the riding steps, but the measures were not taken.

\section{DECEASED WORKER INFORMATION}


The decedent had been employed by the town sanitation department since 2006. As part of the sanitation crew, he worked with a driver and another collection worker to collect refuse, recyclables, and yard debris on designated collection routes. Sanitation department training records showed that he attended the department-wide training "Safety Refuse Truck Operation" in 2014.

\section{EQUIPMENT INVOLVED IN THE INCIDENT}

The refuse collection truck chassis was an International 2011 model with a New Way rear loading trash compactor. The truck was approximately 33 feet long and 10 feet wide, measured between the two front side mirrors which was the widest part of the truck.

Two riding steps were mounted at the rear of the truck, one on each side. The steps were 32 inches long by 10 inches wide, and 17 inches above the ground. There were two warning signs attached to the truck stating: "Do not use riding steps when the vehicle is exceeding $16 \mathrm{kph}(10 \mathrm{mph})$, operating in reverse, or when distance traveled exceeds $0.3 \mathrm{~km}(0.2 \mathrm{mi})$. Do not mount or dismount step when vehicle is in motion. Ride facing the side of the vehicle with both hands on hand holds." The warning sign on the left side of the truck was faded, making some of the wording illegible (photo 1 ).

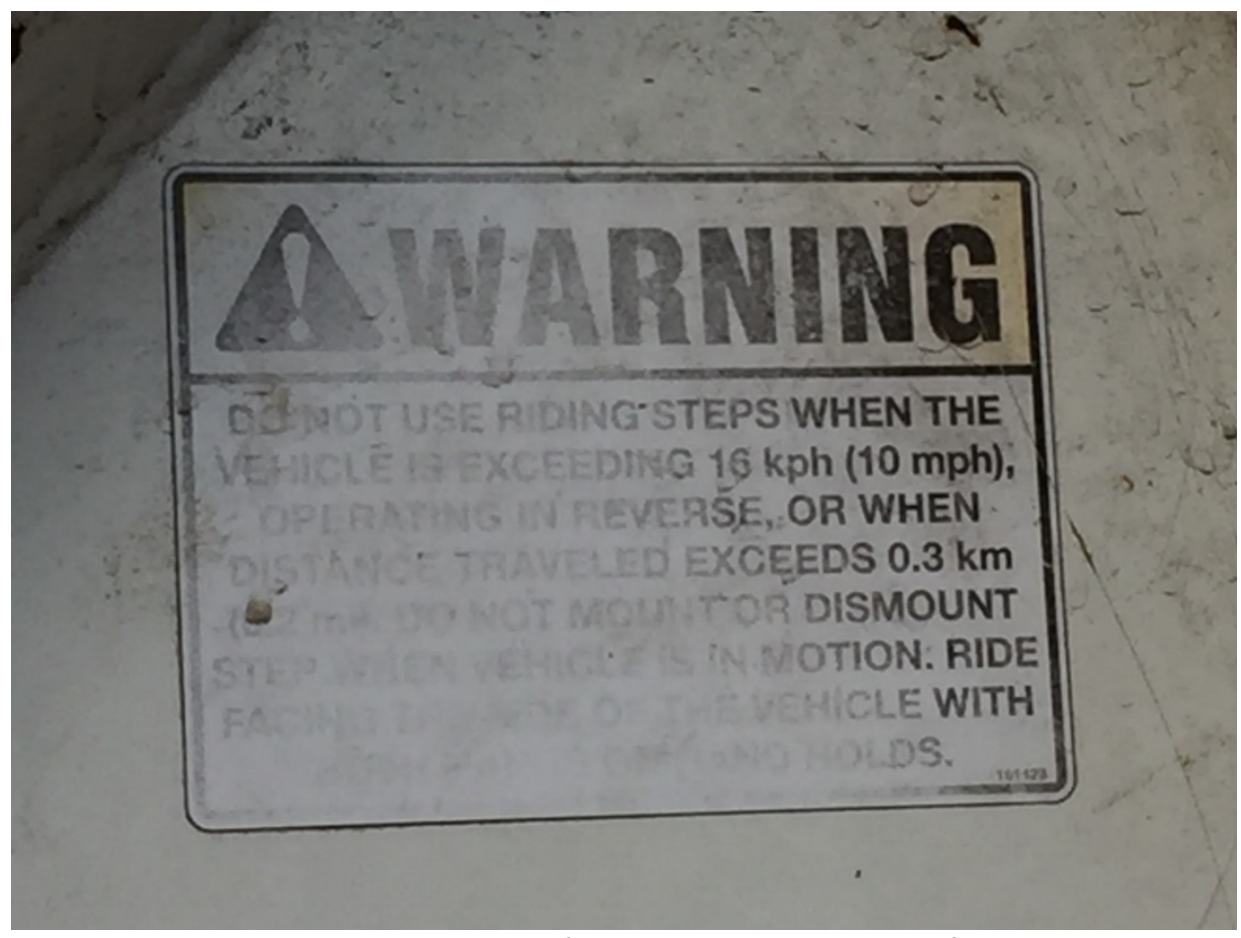

Photo 1. The warning sign on the refuse collection truck was faded with illegible wording (photo courtesy of PESH).

The manufacturer required that the operators inspect the riding steps before each use to make sure that they are in good working condition. Operators are to keep the steps free of all debris, grease, or slick material. The manufacturer also stated that no one 
should ever ride on the steps if the steps are damaged, bent or broken. The step on the driver's side on this truck was bent (photo 2).

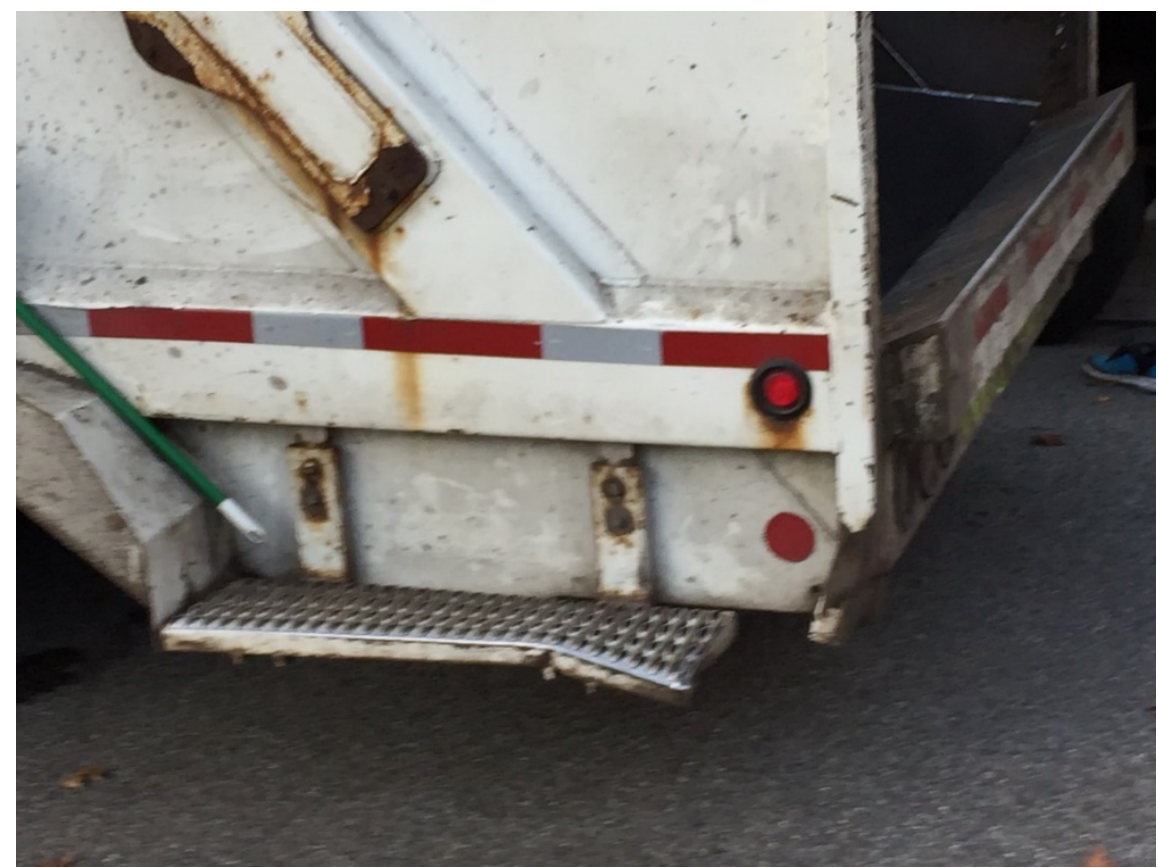

Photo 2. The riding step on driver's side of the refuse collection truck was bent (photo courtesy of PESH).

According to the maintenance records, the truck was inspected, maintained, and repaired a total of 22 times in 2018 prior to the fatal incident in November. Lights, horn, brakes, wipers, mirrors, tires, and tire pressure were regularly checked and repaired. A complete engine service was done in September. The maintenance department also replaced batteries, and changed air, fuel, oil, and carbon filters. There was no documentation showing that the riding steps were ever inspected. The bent step was not reported, nor was a repair scheduled.

\section{REGULATIONS ON REFUSE COLLECTION VEHICLES AND RIDING STEPS}

The ANSI standard "Mobile Refuse Collection and Compaction Equipment Safety Requirements" (ANSI Z245.1-2017) applies to the operation and use of mobile refuse collecting and compacting vehicles. The standard requires that no worker rides the exterior riding steps when the vehicle is backing up, travelling faster than 10 miles per hour, or more than 0.2 miles in distance. In other words, workers can only ride the riding steps when the vehicle is moving forward and travelling no further than 0.2 miles and no faster than 10 miles per hour.

Currently there is no Occupational Safety and Health Administration (OSHA) standard addressing the hazards associated with refuse collection and compaction vehicles, specifically the practice of riding exterior steps. OSHA uses its general duty clause to cite employers for violations of the ANSI standard. PESH, which enforces OSHA and NYS safety and health standards for the public sector in NYS, issued a Program 
Directive in 2006 requiring New York public sector employers to follow the ANSI standard.

New York State Traffic Law (NY Veh \& Traf L § 1233. 2) mandates that no person shall ride or attach himself to the outside of any vehicle being operated upon a roadway. However, vehicles employed by a municipality for local garbage collection are exempt from this law.

New York City prohibits any private sanitation crew member from riding the riding steps of refuse collection vehicles on any public roadways. The Business Integrity Commission (BIC), an agency of the New York City government responsible for regulating the private carting industry, released "Trade Waste Safety Manual" in 2018. The Manual clearly states that workers are not allowed to ride on refuse collection vehicles' riding steps on any public roadways even if they follow the ANSI standard.

\section{INVESTIGATION}

On the day of the incident, the decedent arrived at work at 6 a.m. He was the helper on a three-men refuse collection crew consisting of two helpers and a driver who was the crew chief. The crew operated the rear loading compaction truck to pick up household garbage along a designated city route. The two helpers rode in the cab until they reached the collection site. Once at the collection site, they rode on riding steps between the stops while doing curb-side pickups.

At approximately 2:30 p.m., the crew arrived at the last street of their collection route. The street was approximately 0.7 miles long running east and west with private homes on both sides. ${ }^{1}$ The truck entered the midpoint of the street from a side street.

According to the crew's routine, the truck was to back up all the way to the east end of the street and then move forward for the helpers to pick up garbage on the north side of the street. The total backing distance was approximately 0.34 miles. While the driver operated the truck in reverse, the two helpers were on the riding steps.

The width of the street was estimated at about $30 \mathrm{ft}$. There was an SUV parked on the south side of the street facing east, and a lawn service truck with a trailer parked on the north side of the street also facing east, the wrong direction (Figure 1). The width of the street taken up by the two vehicles was estimated approximately $15 \mathrm{ft}$, which left another $15 \mathrm{ft}$ for the $10 \mathrm{ft}$-wide refuse collection truck to maneuver through in reverse, leaving 2.5 feet of clearance on either side of the refuse collection truck.

The driver backed approximately $330 \mathrm{ft}$ passing the SUV on the driver side. He continued backing with the lawn service truck on the right side when the truck's side mirror contacted the lawn service truck, and the impact broke the mirror. Due to the

${ }^{1}$ The distances and street measurements cited in this report were estimated based on Google Earth available from https://earth.google.com/web. 
broken mirror, the driver could not see the right rear side of the refuse collection truck where the decedent was riding.

The driver continued backing and felt his truck contact the lawn service truck. He stopped and drove forward to pull his truck away. According to the eyewitness, the victim was pinned and crushed in between the lawn service truck and the refuse collection truck. As the refuse collection truck pulled away, the decedent fell to the ground, and he was subsequently run over by the rear passenger side tire of the refuse collection truck. The crew member immediately called 911 and the Emergency Medical Services responded within minutes. The injured worker died on route to the hospital.

PESH conducted a follow up inspection in February 2020, 15 months after the fatal incident. The garbage truck that was involved in the incident was painted and fitted with a new compactor. The old illegible warning sign on the truck was replaced. However, the bent step was still not repaired (Photo 4).

The PESH follow-up inspection documented that the town sanitation department had implemented an annual refuse truck safety training and strengthened the progressive discipline program. The progressive discipline program included 5 days suspension without pay for first violation, 30 days suspension without pay for second violation, and termination for third violation. Workers continued to be allowed to ride the riding steps providing they followed the ANSI standard.

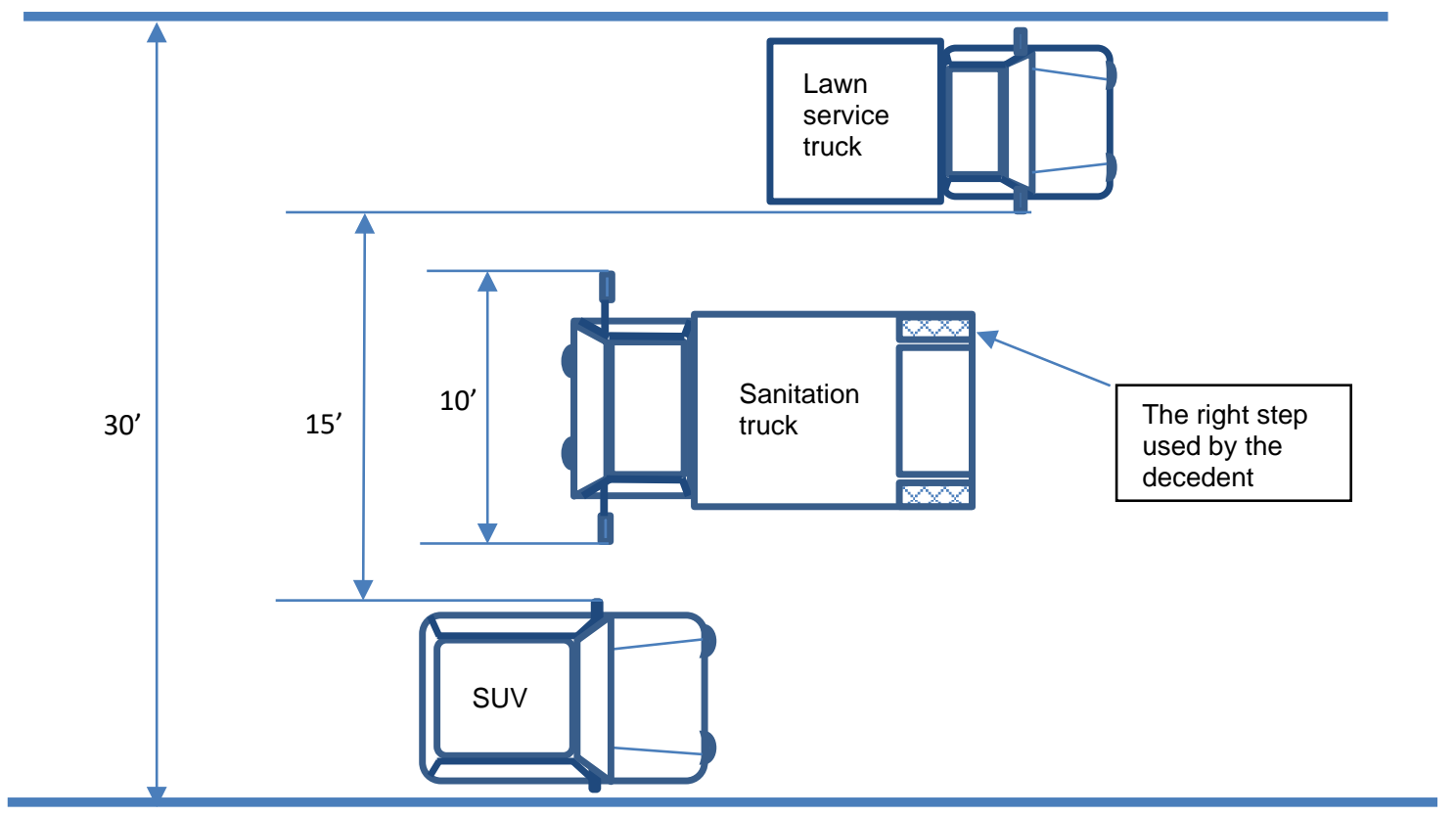

Figure 1. Illustration of the incident site (top view): After the refuse collection truck backed up passing the SUV parked on south side (the driver's side), it contacted the lawn service truck parked on the north side of the street (the right side). The total backing clearance for the refuse collection truck was five feet. 


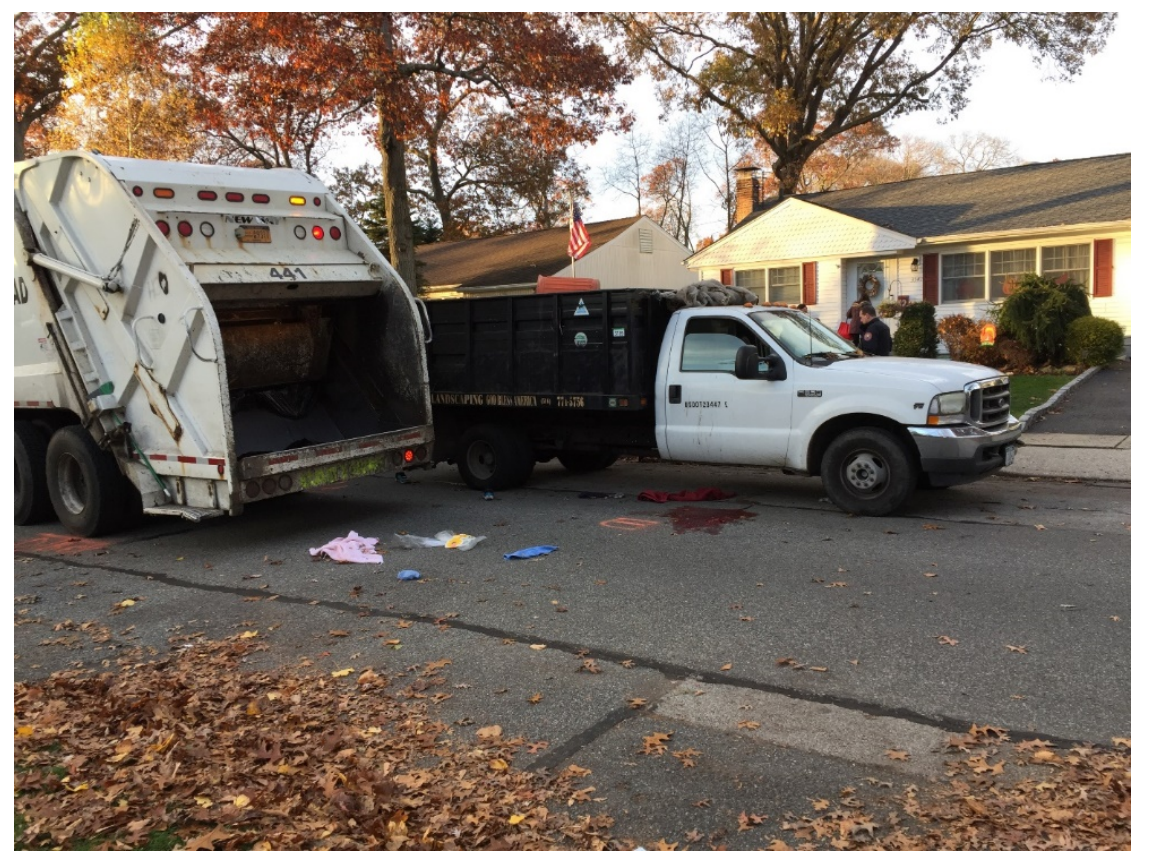

Photo 3. The victim was crushed against the lawn service truck while riding the refuse collection truck on the right riding step when the refuse collection truck was backing up (photo courtesy of PESH). 


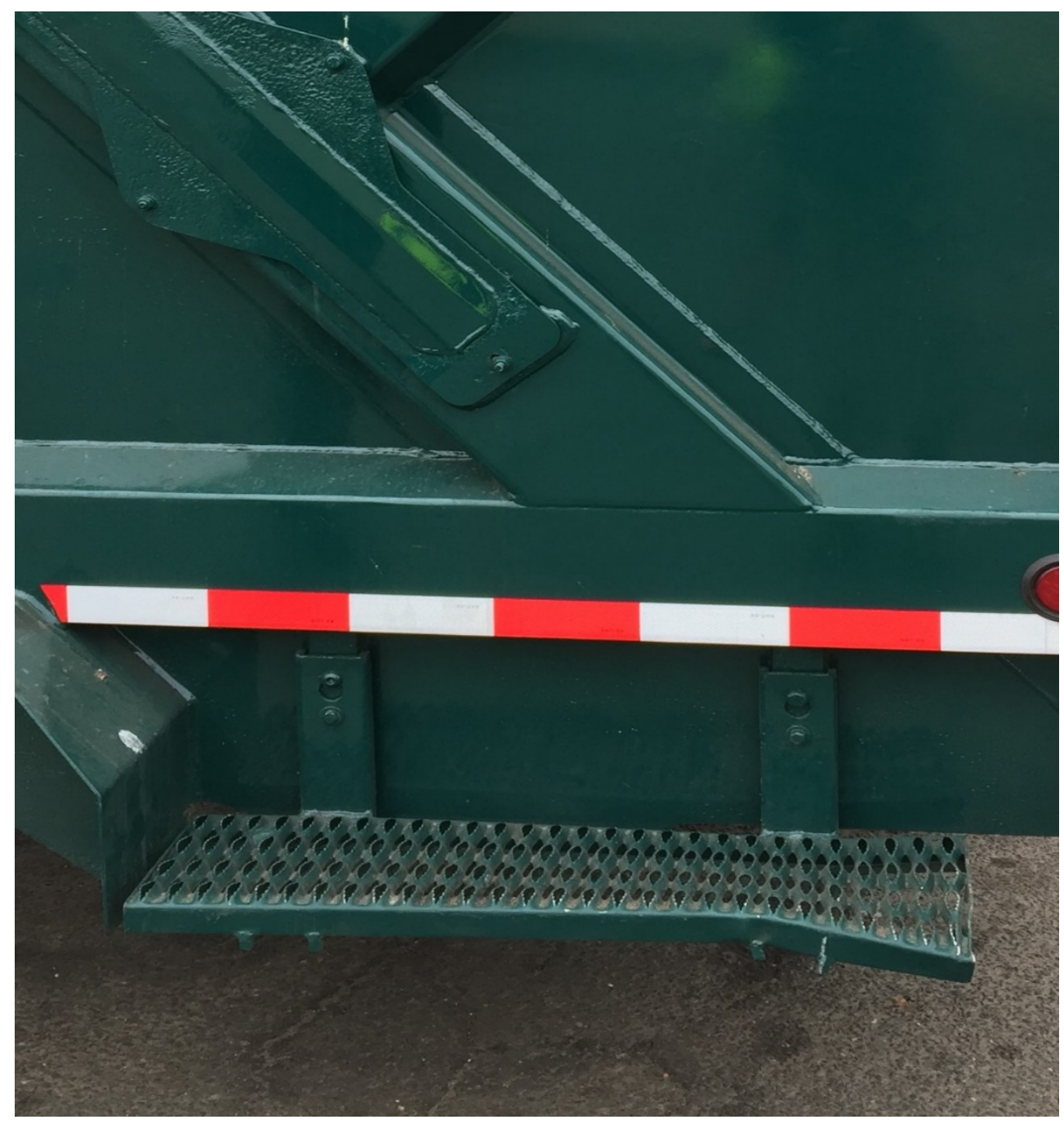

Photo 4. Fifteen months after the fatal incident, the refuse collection truck that was involved in the incident was painted and fitted with a new compactor. The bent step was still not repaired (Photo courtesy of PESH).

\section{CAUSE OF DEATH}

According to the death certificate, the cause of death was hemorrhage due to blunt force torso trauma.

\section{CONTRIBUTING FACTORS}

Occupational injuries and fatalities are often the result of one or more contributing factors or key events in a larger sequence of events. The NY FACE investigation identified the following key contributing factors in this incident:

- Employees were on the riding steps of a refuse collection truck while it was backing up.

- With an SUV parking on one side and a lawn service truck parking on the other side of the street, the total backing clearance for the refuse collection truck was 
estimated at approximately five feet, or 2.5 feet on each side of the refuse collection truck.

- The exterior right-side mirror was broken due to the refuse collection truck contacting the lawn service truck.

- The refuse collection truck driver could not see his right rear side where the decedent was riding due to the broken mirror.

- Employer did not address frequent incidents of employee violation of safety requirements when using the riding steps.

- The progressive disciplinary program was not followed through.

- There was no refuse collection safety training four years prior to the fatal incident.

\section{RECOMMENDATIONS/DISCUSSION}

\section{Recommendation \#1. Employers should consider prohibiting the practice of riding refuse collection truck riding steps by removing these steps.}

Discussion: Both OSHA and PESH allow workers to use the exterior riding steps of refuse collection vehicles provided workers follow the ANSI standard. NY FACE reviewed the OSHA Fatality and Catastrophe Investigation Summary database and identified worker fatality cases associated with riding steps that did not involve violations of ANSI standard. These case scenarios included: Riders lost their grip and fell due to the refuse collection truck making a sharp turn, driving on roads with an incline, or driving on icy, rough, or otherwise damaged roads. In one case the victim lost his grip while trying to avoid being stung by a bee. Victims lost footing due to deformed or damaged riding steps. Tight spaces or narrow streets contributed to victims being crushed between their refuse collection trucks and street objects such as utility poles. Victims were also crushed by other vehicles even when the refuse collection trucks that they were riding did not travel in reverse, faster than 10 miles per hour in speed, and farther than 0.2 miles in distance.

Riding refuse collection trucks on exterior riding steps is a common practice among sanitation workers, even though the practice is not essential for completing the task. Recognizing that the practice is unsafe and high risk, and the ANSI standard has not been effective in preventing serious injuries and deaths, the State of California and New York City had banned the practice of riding on collection truck riding steps. California OSHA rule (Title 8. Group 8. Article 61. Compaction Equipment) clearly stated that no employee shall be standing on rear steps or side steps of a refuse compaction vehicle where the employee cannot be seen by the vehicle operator and is subject to being struck by a vehicle or being thrown off the vehicle.

Numerous factors contributed to widespread and frequent nonobservances of ANSI standards in this case. Due to the nature of the work, direct supervision and constant monitoring of crews on their collection routes was not feasible. The responsibility for following the step riding safety rules was often laid on the sanitation crew members themselves. The employee violation incidents were not thoroughly investigated, and the 
progressive disciplinary program was not followed through. The "on-task" system may also have contributed to the crew's decision to choose to use the riding steps over walking or riding inside the cab since using the riding steps appeared to be faster and easier. To effectively prevent serious injuries and deaths, employers should discontinue or prohibit the use of the riding steps by removing them.

Recommendation \#2: Employers should conduct incident investigations to identify risk and contributing factors and develop specific prevention measures.

Discussion: Between the first fatal incident in 2014 and the second one in 2018, the town recorded 50 non-fatal injury incidents that were associated with riding steps. Workers suffered injuries from falling, slipping, and being caught, struck, or crushed. Employers should conduct thorough incident investigations to identify root causes as well as risk and contributing factors which can be used for making necessary policy or procedural changes to prevent future incidents.

Recommendation \#3: Employers should provide employee training to ensure that workers understand the hazards associated with riding on the riding steps of refuse collection trucks and safety rules.

Discussion: The last department-wide safety training on refuse collection truck operation was conducted in November 2014, four years prior to this fatal incident. The 2014 training was provided in responding to the first fatality which also involved a town sanitation worker killed while riding the exterior riding step. Since then no annual or refresher training was provided.

Employers should provide annual, refresher, and specialized training for employees to learn hazards and risk factors associated with each task. Through training, workers can gain the knowledge and skills to do their work safely and avoid creating hazards that could place themselves or others at risk. Refresher trainings should be provided when a change in operation procedure or equipment occurs or new hazards were identified.

Following an injury incident, a near miss, or employee violation, employers should provide additional training to review the root cause and contributing factors that lead to the incident or near miss. Employers should discuss with employees the importance of following safety rules, so that workers can learn from the incidents and review the safety rules as well as their own roles and responsibilities in preventing work-related injuries.

Recommendation \#4: Employers should conduct job hazard analysis (JHA) to identify hazards and risk factors and develop effective measures to prevent worker injuries associated with refuse collection truck riding steps.

Discussion: A JHA focuses on the relationship between the worker, the task, the tools, and the work environment so that the hazards associated with each component and each step of the task can be identified before they occur. It is critical to conduct a JHA 
on refuse collection, which is not only a task with high injury rates, but also a task in which one single human error or negligence could lead to severe injuries or deaths.

The employer in this case required that all sanitation crews follow the ANSI standards when operating refuse collection trucks and using the riding steps. However, violations were frequent and widespread. The routine of the sanitation crew involved in the fatal incident was to reverse their truck approximately 0.34 miles to the end of the street with two helpers on the riding steps before moving forward to pick up garbage. While conducting a JHA, employers should examine and review each collection route to identify hazards and risk factors. Based on the hazards identified through the JHA, employers can then develop and implement appropriate prevention measures and standard safe work procedures for workers to follow. Employers should review the routes with the collection crews to ensure that they understand the risk and do not deviate from the designated routes and strictly follow the ANSI standard.

Recommendation \#5: When implementing a progressive disciplinary program, employers should ensure that appropriate disciplinary actions are carried out and followed through.

Discussion: The town sanitation department established a progressive disciplinary program with the intention to intervene, deter, and correct employee misconduct and violations. However, the program had not been effectively implemented prior to the fatal incidents. Should the town sanitation department choose to continue implementing the program, management should ensure that proper disciplinary actions are carried out and followed through.

\section{Recommendation \#6: Employers should ensure that the riding steps are} inspected regularly, and damaged steps are repaired immediately.

Discussion: The refuse collection truck that was involved in the incident had a riding step that was bent. According to the OSHA fatality investigation records, sanitation workers have suffered fatal injuries from falling or slipping off riding steps that were bent or damaged. Manufacturers prohibited operators from riding on the steps that are damaged, bent, or broken and required operators to keep the steps free of all debris, grease, or slick material. Employers should ensure that the riding steps are regularly inspected to make sure that there is no damage to the steps and that attachment is secure. Vehicles with damaged steps should be removed from service, and the damaged steps should be repaired or replaced in a timely manner.

\section{Recommendation \#7: Employers should consider implementing an automated system for refuse and recyclable material collection.}

Discussion: More municipal and private refuse and recyclable material collectors have switched to an automated collection system which is composed of collection vehicles that have a mechanical arm with an automated lift and standardized waste containers. Residents place the containers at the curb, and the driver maneuvers the arm from the 
controls inside the cab of the refuse collection truck to pick up the container, empty it into the vehicle, and return the container to the curbside.

Employers should consider implementing the automated collection system since the automated trucks eliminate the serious injury risk associated with workers riding on the exterior riding steps and alleviate heavy lifting; hence reducing worker compensation claims and minimizing insurance costs.

\section{Recommendation \#8: In-depth studies should be conducted to assess the effectiveness of the current safety regulations on refuse collection truck riding steps.}

Discussion: NY FACE staff reviewed approximately 555 worker fatality cases associated with refuse collection trucks that were investigated by OSHA between 1984 and 2018. The preliminary review identified a total of 155 cases, approximately $28 \%$ of all cases, that involved victims using riding steps. OSHA allows the practice, provided workers abide the ANSI requirements. In-depth review identified fatality cases that did not involve ANSI violations: Victims were killed even when the refuse collection trucks that they were riding did not travel in reverse, faster than 10 miles per hour, and father than 0.2 miles in distance. Workers have lost their grip and fell off the steps due to the refuse collection truck making a sharp turn or driving on inclined, rough, icy, or damaged roads. Damaged or deformed riding steps and tight space or narrow streets have also contributed to worker deaths.

The practice of riding refuse collection trucks on exterior riding steps involves significant risk for serious injury including death. There is an urgent need for studies to identify the causal and contributing factors associated with the practice, assess the factors that might influence worker behaviors, provide evidence-based information for developing best industry management practices for safety, and evaluate the effectiveness of the current safety regulations. The solid waste industry, governmental regulatory agencies, and safety and health researchers should work together to facilitate and conduct these studies.

\section{DISCLAIMER}

Mention of any company or product does not constitute endorsement by the NY FACE and NIOSH. In addition, citations to websites external to NY FACE and NIOSH do not constitute NY FACE and NIOSH endorsement of the sponsoring organizations or their programs or products. Furthermore, NY FACE and NIOSH are not responsible for the content of these websites. All web addresses referenced in this document were accessible as of the publication date. 


\section{REFERENCES}

American National Standards Institute (ANSI). Mobile Refuse Collection and Compaction Equipment-Safety Requirements. ANSI 245.1-2017.

National Safety Council, Safety+Health. Sanitation worker safety still a concern for SWANA despite 'small decline' in deaths. Retrieved June 22, 2020 from: https://www.safetyandhealthmagazine.com/articles/19618-sanitation-worker-safety-stilla-concern-for-swana-despite-small-decline-in-deaths

New York State Department of Labor, Division of Safety and Health, Public Employee Safety and Health Bureau. PESH Safety Directive. Surveys involving refuse collection vehicles. Retrieved June 22, 2020 from: https://cseany.org/wpcontent/uploads/2016/02/PESH Sanitation Directive.pdf

2015 New York Laws, VAT - Vehicle \& Traffic, Title 7 - RULES OF THE ROAD Article 34 - (1230 - 1241) OPERATION OF BICYCLES AND PLAY DEVICES 1233 - Clinging to vehicles. Retrieved June 22, 2020 from:

https://law.justia.com/codes/new-york/2015/vat/title-7/article-34/1233/

City of New York Business Integrity Commission. Trade Waste Safety Manual. Retrieved June 22, 2020 from:

https://www1.nyc.gov/assets/bic/downloads/pdf/safety/bic safety manual 022018 final . pdf

Occupational Safety and Health Administration. OSHA Act of 1970 (general duty clause) Retrieved June 22, 2020 from: https://www.osha.gov/laws-regs/oshact/section5duties

Occupational Safety and Health Administration. Fatality and Catastrophe Investigation Summaries. Retrieved June 22, 2020 from:

https://www.osha.gov/pls/imis/accidentsearch.html

National Institute for Occupational Safety and Health. Preventing Worker Injuries and Deaths from Moving Refuse Collection Vehicles. Retrieved June 22, 2020 from https://www.cdc.gov/niosh/docs/97-110/default.html.

National Institute for Occupational Safety and Health. Fatality Assessment and Control Evaluation (FACE) Program. NIOSH FACE Reports. Sanitation worker runover after falling from trash collection vehicle-Virginia. Retrieved June 22, 2020 from https://www.cdc.gov/niosh/face//n-house/full9411.html

Massachusetts State Fatality Assessment and Control Evaluation program. Refuse Collector was Fatally Injured when Struck by a Backing Refuse Collection Truck. Retrieved June 22, 2020 from https://www.cdc.gov/niosh/face/pdfs/11MA019.pdf. 
Massachusetts State Fatality Assessment and Control Evaluation program. Municipal Laborer Dies after Falling Off the Back of a Forward Moving Refuse Collection.

Retrieved June 22, 2020 from

https://www.cdc.gov/niosh/face/stateface/ma/09MA020.html.

Massachusetts State Fatality Assessment and Control Evaluation program. City Laborer Dies after Falling Off a Moving Refuse Collection Truck. FACE Facts. Safety Alert. Retrieved June 22,2020 from https://www.mass.gov/files/documents/2016/07/xl/refusetruck.pdf.

Cal/OSHA-Title 8 regulations. Subchapter 7. General Industry Safety Orders. Group 8. Points of Operation and Other Hazardous Parts of Machinery. Article 61. Compaction Equipment. §4355. Operating Rules for Compaction Equipment. Retrieved June 22, 2020 from https://www.dir.ca.gov/title8/4355.html.

Marc J. Rogoff, Donald Ross, Richard E. Lilyquist, Jeffrey L. Wood. Automated Waste Collection - How to Make Sure It Makes Sense for Your Community. Retrieved June 22, 2020 from https://scsengineers.com/wpcontent/uploads/2015/03/Rogoff Automated Waste Collection.pdf

\section{INVESTIGATOR INFORMATION}

This investigation was conducted by NY FACE, Bureau of Occupational Health and Injury Prevention, Center for Environmental Health, New York State Department of Health.

\section{ACKNOWLEDGEMENT}

The NY FACE staff would like to acknowledge the PESH Long Island Area Office for assisting this investigation. 